\title{
Development of a large-area, low-cost solar water-heating system for South Africa with a high thermal energy collection capacity
}

\author{
Monga F. Twite, Lukas W. Snyman*, Johan de Koker, Dayo Yusuff \\ Department of Electrical Engineering, College for Science Engineering and Technology, University of South Af- \\ rica, Florida, Johannesburg, P.O. Box 392, UNISA, 0003, South Africa.
}

\begin{abstract}
A low-cost heat-exchanger system that can be used in high-pressure/low-pressure isolated solar water-heating systems in South Africa was developed for household applications. The combination of a copper coil and electrical heater allowed for isolation of the high-pressure and low-pressure sections of the system and enabled the utilisation of large low-cost solar heat-absorber platforms that operated at low pressure with a low risk of fouling and leaking. The design comprised a copper coil heat exchanger to be installed inside a conventional geyser, to replace the normal heating element and thermostat system in a conventional commercially available household geyser. The electric heating element still supplements the system in low solar energy conditions. The circulation in the system is created by a small separate photovoltaic panel and a circulation pump. An integrated switch allows the system to alternate between conventional electrical heating and solar water-heating according to prevailing weather conditions. Current tests show that the system of $15 \mathrm{~m}^{2}$ area can be installed at a cost of approximately ZAR 10 000-12 000. The system can provide hot water at approximately 12 cents per $\mathrm{kWh}$, with a total heat storage capacity of up to $10 \mathrm{kWh}$ per day. This implies a saving to the customer of up to ZAR 600 per month. The accumulated saving to a household over the tenyear lifetime of the product is estimated at ZAR 200 000. As the thermal energy storage capacity of current systems as available on the local market is approximately $1 \mathrm{kWh}$ per day for a $2 \mathrm{~m}^{2}$ collector. A typical increase in thermal energy collection capacity of tenfold more than the capability of conventional systems on the market is hence achieved. The system offers implementation possibilities for South Africa's low-cost housing schemes and can provide for creating numerous new business and job opportunities on the African continent with its abundant solar irradiation resources.
\end{abstract}

\author{
Journal of Energy in Southern Africa 30(1): 49-59 \\ DOI: http://dx.doi.org/10.17159/2413-3051/2019/v30i1a5226 \\ Published by the Energy Research Centre, University of Cape Town ISSN: 2413-3051 \\ http://journals. assaf.org.za/jesa \\ Sponsored by the Department of Science and Technology
}

Corresponding author: Tel: +27 11471 2299;

email: snymansvirginia297@gmail.com 


\section{Introduction}

The objective of this study was to develop a low-cost solar water-heating system using a standard commercially available geyser that has a simple design, yet is reliable and efficient enough to collect large quantities of solar energy at very low cost for ordinary households in South Africa. The design was developed for low-cost urban housing developments as well as underdeveloped rural areas in South Africa. The study reports on the results obtained from the development of a low cost thermal energy and solar water heating system, where an effective lowcost heat exchanger was added to a conventional commercially available solar geyser in South Africa. Solar water-heating systems that are currently available in South Africa and Africa are mostly far out of the reach of low-income households - the current vendor supply cost in South Africa typically ranges at ZAR 10 000-30 000 per unit for moderate capacity systems (Price Check SA Co, 2018). Thermal energy is transferred from a low-pressure large area thermal energy absorber system to the solar geyser through a novel heat exchanger heating element design and where the high pressure from the standard urban water supply grid was isolated from the low pressure thermal energy collection system. This enabled the collection of ten folds higher thermal energy as compared to collection capacity of other systems as are available on the market in South Africa and drastically reduce the price of effective stored and usable thermal energy for the household. Low cost materials as are available in supply stores were used for the construction of the system.

\section{Experimental}

\subsection{Overview: Conceptual design}

A low-cost large-area solar heat absorber was developed for his study at the University of South Africa (UNISA) Florida research laboratories, Johannesburg. Figure 1 shows a schematic diagram indicating the basic components of the system. The diagram shows a geyser (hot-water storage reservoir), which incorporates a low-cost heat-exchange coil system, a photovoltaic panel and pump, as well as electronic switchover systems to automate the switchover between electrical heating and solar heating.

The electrical geyser tank chosen for this study had a capacity to retain 150 litres of water, which can supply enough hot water for a family of five. Heat transfer in the heat exchanger is done by both conduction and convection. Where possible, components that are generally available to South African households are incorporated in the design of the adaptive system. The system had two electric circuits. The first one, a direct current (DC) and the second, an alternative current (AC) circuit. The DC circuit starts the pump, which causes the water to circulate from the solar collector through the heatexchange system. The AC circuit starts when the DC fails, when there is not enough solar energy available to drive the circulation pump or when the temperature in the geyser reservoir drops significantly. This incorporates adequate default routing in the design should some components fail during operation or should fouling of the circulation occur. In this case, the thermostat $(\mathrm{TH})$ allows the $\mathrm{AC}$ power to flow through the coil of the electromagnetic relay.

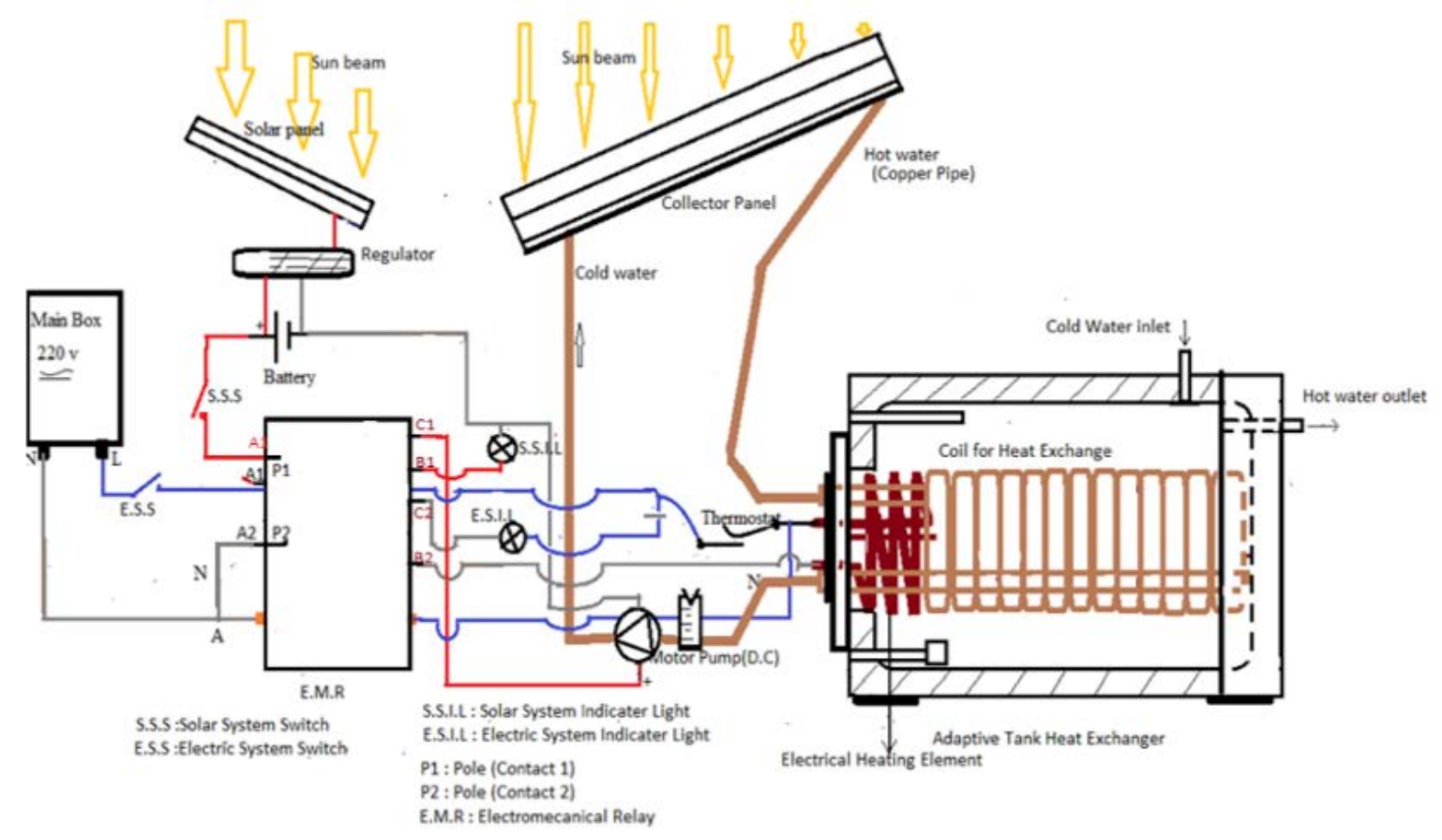

Figure 1: Schematic layout of the hybrid solar-electric water-heating system using a copper coil heat-exchange system. 
This interrupts the DC circuit as switch A1 is opened. At the same time, switch A2 closes and the geyser's electric heating element connects to grid electricity and, therefore, heat the water in the tank. At this point, $\mathrm{P} 2-\mathrm{C} 2$ switches on the solar system indicator light to indicate that the solar water-heating system is operating. A low-cost relay-based system design has been implemented, which simplifies operation and eliminates the need for computer technology. There is no need to locate the tank above the solar heat collectors because the system does not need thermo-siphoning. This increases the application of the system in various household scenarios and enables large areas of solar heat collection to be implemented, while also making it possible to incorporate the system in the existing roof designs at a high level. The coil of the relay is alternately connected and disconnected to ensure that the system can utilise either solar energy or electricity, depending on climatic conditions.

The system is, however, designed to function primarily as a solar water heater. The heat-exchange coils have been designed to replace the normal heating element and thermostat systems in conventional geysers. The mounting screws and flange of the thermostat unit were replaced with the copper heat-exchange coil and electric heating subassembly. Also important is that the water pressure in the solar collection and circulation system is low - this differs completely from the high-pressure system used in a normal household geyser. The low water pressure improves the reliability and lifetime of the system. The low-pressure heat-absorbing capability of the system ensures that it can be manufactured from low-cost materials. This improves the reliability of the system and allows the application of the system in low-cost housing developments and rural areas in South Africa. The design of the heat-exchange coils and the circulation rate are of paramount importance in such a system as they determine the rate of heat exchange between the solar heat absorber and the geyser reservoir.

Figure 2 shows a picture of the final complete large-area low-pressure solar heat-collection system developed at the UNISA Florida research laboratory and under operation. The specific system utilises a conventional galvanised Inverted Box Rib (IBR) roof sheeting system with strips of black polyethylene piping aligned and suspended in the troughs of the sheeting. The circulation system in the piping was designed to enhance heat absorption in the lowtemperature zones, while reducing heat loss because of radiation and air convection in the high-temperature zones of the piping. A good compromise is, therefore, reached between efficient heat collection and keeping the cost of the design low.

The exact design is the topic of filed South African Patents RSA Patent No. 1508 of 2012 and RSA
Patent No. 05297 of 2016) with Unisa as the intellectual property owner (SA Patent Journal, 2012 and 2016). The RSA Patent 567745 of 2008 describes an innovative electronic controller that can be used with the system and that can be coupled to the electricity distribution box of a household (SA Patent Journal, 2008).

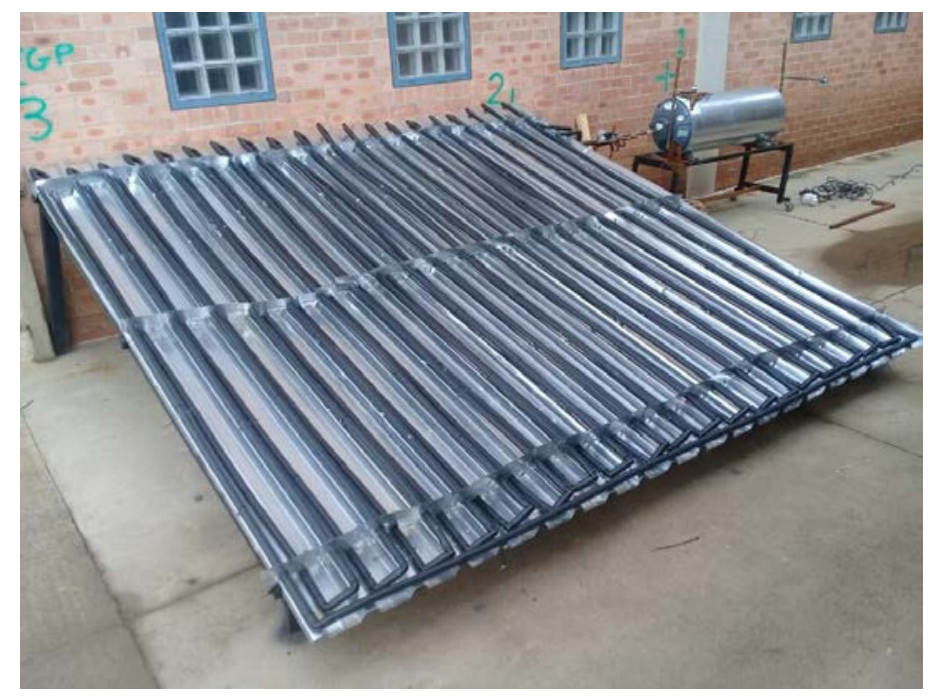

Figure 2: The low-cost large-area heatabsorbing system developed at the Unisa Research Development Laboratories. The design incorporates suspended black piping on reflective galvanised sheeting to increase the absorption of heat in the pipes from both above and below.

\subsection{Design of the heat-exchanger coil}

The heat-exchanger design was a very challenging part of the system design. To achieve the design basis and sizing of a heat exchanger, the thermal energy transfer considerations as published in handbooks by Lienhard and Lienhard (2011), Saha et al. (2016) and Schreyer (2011) were used. The system was designed to be used with an existing commercially available electric geyser, namely, a standard 150-litre household geyser with an inlet port with an inside flange diameter of $120 \mathrm{~mm}$. These parameters would be the main constraint parameters of the system. The main goal of the design was that the heat-exchange coil had to fit easily into the port of the geyser, although small additional changes could be made to the system to accommodate an electrical heating element and a thermostat. The design of the heat exchanger was determined by the dimensions of piping and the sizing of coils that would generally be available from building supplies stores in South Africa. The study then chose final piping dimensions and operational parameters, including the circulation flow rate, that would optimise the heat transfer from the coil to the water inside the geyser, as predicted by preliminary theoretical calculations. 


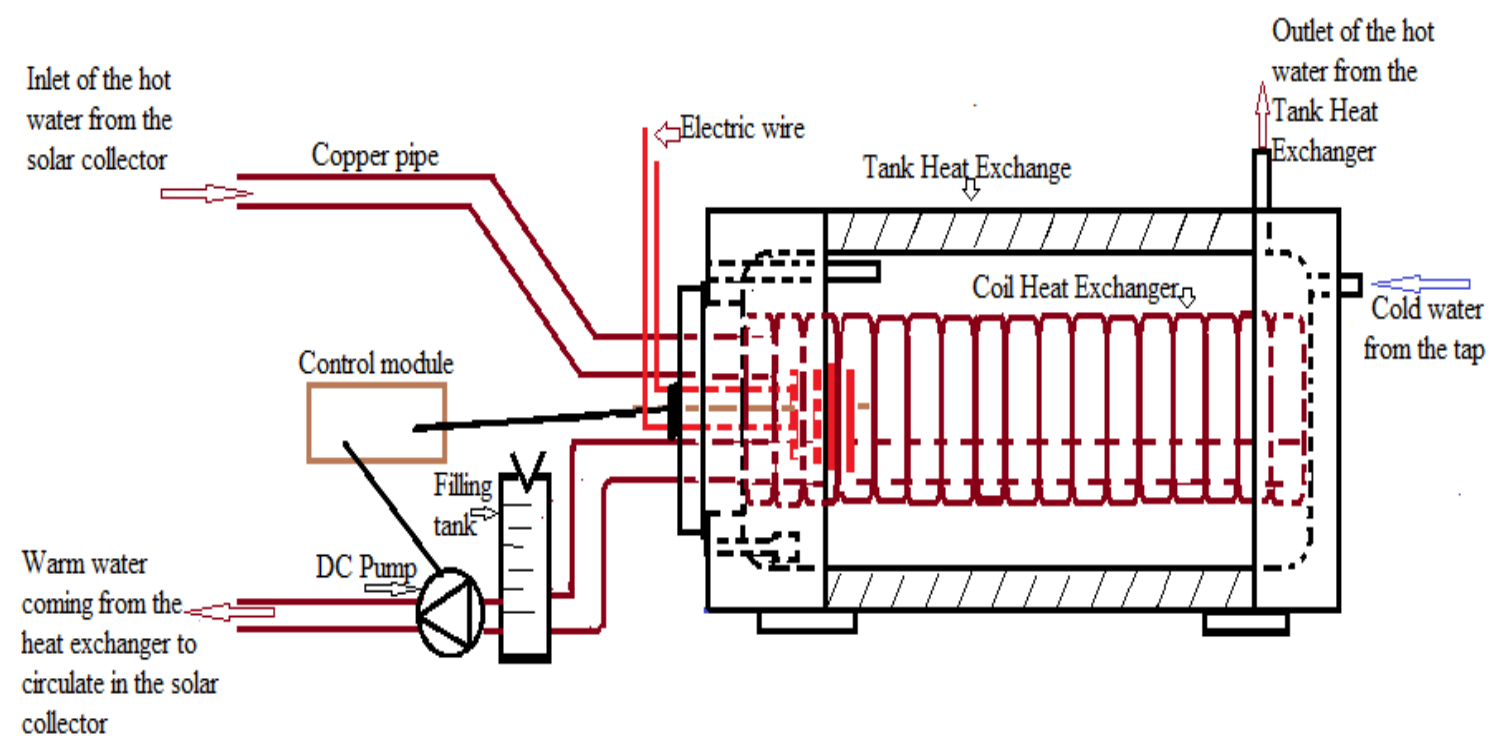

\section{Figure 3: Schematic illustration of the designs of the copper piping heat-exchange coils as developed in this study, with an electrical heating element.}

Figure 3 shows the eventual conceptual design of the heat-exchange coil assembly. In this case, the heat-exchanging copper coil was merely added to an existing heater thermostat system by drilling extra holes in the side flange of the system to accommodate the inlet and outlet of the copper coil. The new adaptive unit could easily replace an existing electrical heater and thermostat unit by merely replacing it with the adaptive copper coil heat-exchange system.

Copper was chosen as conduction material. Dehydrated refrigeration tube was chosen for the coil material because it is commercially available at a reasonable cost and is easily processed. Copper piping is widely considered to be ideal for supply lines as it is resistant to corrosive elements; high temperatures and high pressure; and, generally, maintains its structural integrity with age. An empirical approach was followed by choosing piping diameters and the coil diameter according to the restrictions posed by the capacity of the reservoir tank (150 litres) and the inlet port flange of the geyser $(120 \mathrm{~mm}$ diameter). Piping thicknesses were chosen based on piping designs that would be readily available from building supplies stores in South Africa. Piping lengths were chosen according to available space, as allowed by the lateral length of the geyser after allowing maximum spiralling. The coil spiral diameter was chosen based on the space available at the inlet port of the reservoir (geyser).

Then, detailed theoretical thermal conduction and pressure-flow analyses were undertaken to ensure adequate flow rates and laminar flow, and pipe thicknesses and lengths were refined based on these theoretical analyses. The chosen diameter of the coil spirals was as large as could be accommodated by the inlet port to reduce possible turbulent effects ow- ing to curvatures during flow. The overall heat transfer is generally a function of the general resistance to the flow of heat and is usually based on analyses of component resistances. We know that heat flow from the hot material to a cold material is given by Equations 1 and 2 .

$$
\begin{aligned}
& \Phi_{\max }=\mathrm{q}_{\mathrm{tc}} * \Delta \mathrm{T}_{\max } \\
& \mathrm{K}=\Phi_{\max } / \mathrm{S}_{\mathrm{m}} * \Delta \mathrm{T}_{\mathrm{lm}}
\end{aligned}
$$

where $\Phi_{\max }$ is the heat transferred from a hot fluid to a cold fluid, $\mathrm{q}_{\mathrm{tc}}$ is the thermal flow of cold water, $\Delta \mathrm{T}_{\max }$ is the maximum variation of temperature, $\mathrm{K}$ is the global heat-exchange coefficient, $S_{m}$ is the average surface of heat exchange, and $\Delta \mathrm{T}_{\mathrm{lm}}$ is the average logarithmic temperature difference.

For the copper piping, the surfaces of heat exchange, $S_{h}$ and $S_{c}$, related to the inner and outer surfaces of the piping; and also the coefficients of global heat exchange, $\mathrm{kc}$ and $\mathrm{k}_{\mathrm{c}}$ were introduced. A mathematical model was used to analyse the transfer of heat from the heating fluid to the thermal storage reservoir and the time of heat exchange, as well as to determine the thermal efficiency.

Consider the input $\left(\mathrm{T}_{\mathrm{hi}}\right)$ and output $\left(\mathrm{T}_{\mathrm{ho}}\right)$ temperatures of hot and cold water and the number of coils, the external diameter $\left(D_{o}\right)$ with $r_{\text {out }}$, the inner diameter $\left(D_{\text {in }}\right)$ with $r_{\text {in }}$, and the pipe's thickness $(\mathrm{mm})$.

The circumferences of one spiral of the coil is given by Equation 3.

$\mathrm{C}_{\mathrm{o}^{\prime}}=2 \pi \mathrm{r}_{\mathrm{o}^{\prime}}$

where $r_{\mathrm{o}^{\prime}}=\left(\mathrm{Do}^{\prime} / 2\right)$ is the inlet diameter of tube coil. 
The number of turns was then calculated as: $\mathrm{N}=\frac{\text { inside length of geyser }}{\text { outside diameter of pipe }}$.

The total length of the coil in the geyser was determined using Equation 4.

$$
\mathrm{L}_{(\mathrm{t})}=\mathrm{C}_{\mathrm{o}^{\prime}} * \mathrm{~N}^{\prime}+\mathrm{L}_{(\mathrm{in})} \text {. }
$$

Moreover, the inner volume $(\mathrm{V})$ would be: $\mathrm{V}=\pi \mathrm{r}^{2}$ * $\mathrm{L}_{(\mathrm{t})}$, in which $\mathrm{r}$ is the $\mathrm{D} / 2$ inlet diameter of the tube. The $\pi r^{2}$ is already known as $A$; thus, $V=$ $A * L_{(t)}$ (litres).

The internal volume of the coil $\mathrm{V}=\mathrm{A} * \mathrm{~L}_{(\mathrm{t})}$, where A was the cross-section area of the coil, $\mathrm{L}_{t}$ was the total length of the coil; and $\mathrm{A}=\pi \mathrm{r}^{2}$ in $\mathrm{m}^{2}$; and $\mathrm{r}$ was the inner diameter of the pipe.

The heat-exchange surface was then defined according to Equation 5.

$$
\mathrm{S}_{\mathrm{m}}=2 \pi \mathrm{r} * \mathrm{~L}_{(\mathrm{t})}+2 \pi \mathrm{r}^{2}\left(\mathrm{~m}^{2}\right)
$$

The temperature difference between the inside and the outside of the pipe was defined according to Equation 6.

$$
\Delta T \operatorname{lm}=\frac{(T h o-T c i)-(T h i-T c o)}{\log \left(\frac{T h o-T c i}{T h i-T c o}\right)}
$$

where o and i refer to the respective inside and outside parameters of the pipe.

The section of heat passage was then defined by Equation 7.

$$
\mathrm{S}_{\mathrm{p}}=\frac{\pi}{4} *(\mathrm{D})^{2}\left(\mathrm{~m}^{2}\right)
$$

As $S_{p}$ and the maximal volume flow rate $\left(Q_{v}\right)$ of the pump were known, the speed of the fluid could be calculated as follows:

$$
\mathrm{V}^{\prime}=\frac{Q v}{S p} \mathrm{~m}^{3} / \mathrm{min}
$$

The maximum heat flow in the heat exchanger is given by Equation 8 .

$$
\Phi_{\max }=\mathrm{q}_{\mathrm{tm}}=* \Delta \mathrm{T}_{\max } \Rightarrow \mathrm{qt}_{\text {min }}=\mathrm{q}_{\mathrm{tc}}
$$

where $\Delta \mathrm{T}_{\max }=\mathrm{T}_{\mathrm{hi}}-\mathrm{T}_{\mathrm{ci}}\left({ }^{\circ} \mathrm{C}\right)$ and

$$
\begin{aligned}
& \mathrm{q}_{\mathrm{th}}=\mathrm{q}_{\min } * \mathrm{C}_{\mathrm{p}} \\
& \Phi_{\mathrm{h}}=\mathrm{q}_{\mathrm{tc}}\left(\mathrm{T}_{\mathrm{hi}}-\mathrm{T}_{\mathrm{ho}}\right) \text { Watts } \\
& \Phi_{\mathrm{c}}=\mathrm{q}_{\mathrm{tc}}\left(\mathrm{T}_{\mathrm{co}}-\mathrm{T}_{\mathrm{ci}}\right) \\
& \Phi_{\min }=\Phi_{\mathrm{c}} / \Delta \mathrm{T}_{\max }
\end{aligned}
$$

The thermal efficiency was defined according to Equation 9.

$$
(\mathrm{E})=\frac{(T c o-T c i)}{(T h i-T h o)} * \frac{1}{R}
$$

with $\mathrm{R}=\frac{(T c o-T c i)}{(T h i-T c i)}$ the coefficient of imbalance. 10.

The overall coefficient $(\mathrm{K})$ is given by Equation

$$
\mathrm{K}=\frac{\Phi \mathrm{h}}{S m * \Delta T l m}
$$

The time that the exchanger would take to heat the water in tank is calculated using Equations 11 and 12.

$$
\begin{aligned}
& \mathrm{t}_{\text {min }}=\mathrm{q}_{\mathrm{c}} * \mathrm{~V}^{\prime} / \Phi \text { max } \text { (minutes) } \\
& \mathrm{t}_{\text {max }}=\mathrm{q}_{\mathrm{c}} * \mathrm{~V}^{\prime} / \Phi_{\text {min }} \text { (minutes) }
\end{aligned}
$$

Eventually, two coil designs that best satisfied all practical and theoretically considerations were chosen. These were selected to be manufactured as prototypes and to be empirically tested in a test system. In the final experiments, predictions about flow rates were empirically tested by applying different sizes of pumps as circulation media. A pump size was chosen that allowed for the highest possible circulation rate without introducing excessive visually observed turbulence at the outlet of the coil assembly. Table 1, Figure 3 and Figure 4 give an overview of the final specifications and characteristics of the heat exchanger system developed in this study.

Table 1: Major derived theoretical values and projected total heating times for the geyser with the final chosen prototype pipe thicknesses and lengths.

\begin{tabular}{ccccc|ccccc}
\hline \multicolumn{2}{c}{ Heat-exchanging coil design $B$ (thick piping coil) } & \multicolumn{5}{c}{ Heat-exchanging coil design A (thin piping coil) } \\
\hline Length & $\begin{array}{c}\text { Temperature } \\
\left({ }^{\circ} \mathrm{C}\right)\end{array}$ & $\begin{array}{c}\text { Heating } \\
\text { time }\end{array}$ & $\begin{array}{c}\text { Thermal } \\
\text { efficiency }\end{array}$ & Length & Temperature $\left({ }^{\circ} \mathrm{C}\right.$ ) & $\begin{array}{c}\text { Heating } \\
\text { time }\end{array}$ & $\begin{array}{c}\text { Thermal ef- } \\
\text { ficiency }\end{array}$ \\
\hline$m$ & Inlet & Outlet & min & $\%$ & $m$ & Inlet & Outlet & min & $\%$ \\
\hline 17.5 & 100 & 50 & 159 & 0.7 & 14.1 & 100 & 50 & 153 & 0.7 \\
17.5 & 70 & 50 & 257 & 0.6 & 14.1 & 70 & 50 & 188 & 0.6 \\
\hline
\end{tabular}


Figure 4 shows schematic diagrams of the final designs of the two heat exchanger coils as well as dimensions of the coils. Both coils were $114 \mathrm{~mm}$ in diameter (outer diameter), so that they could fit into the neck of the geyser, which was $115 \mathrm{~mm}$ in diameter. Each had a set of coils not exceeding $1200 \mathrm{~mm}$ in length, which is the inner length of the flange of the inlet port of the geyser. The final two spiralled copper pipes were (1) $12.7 \mathrm{~mm}$ in diameter, 0.71 $\mathrm{mm}$ thick and $15.24 \mathrm{~m}$ long (Heat-exchanging Coil A); and (2) $15.8 \mathrm{~mm}$ in diameter, $0.63 \mathrm{~mm}$ thick and $15.24 \mathrm{~m}$ long (Heat-exchanging Coil B). They were constructed and used in the tests and experiments.
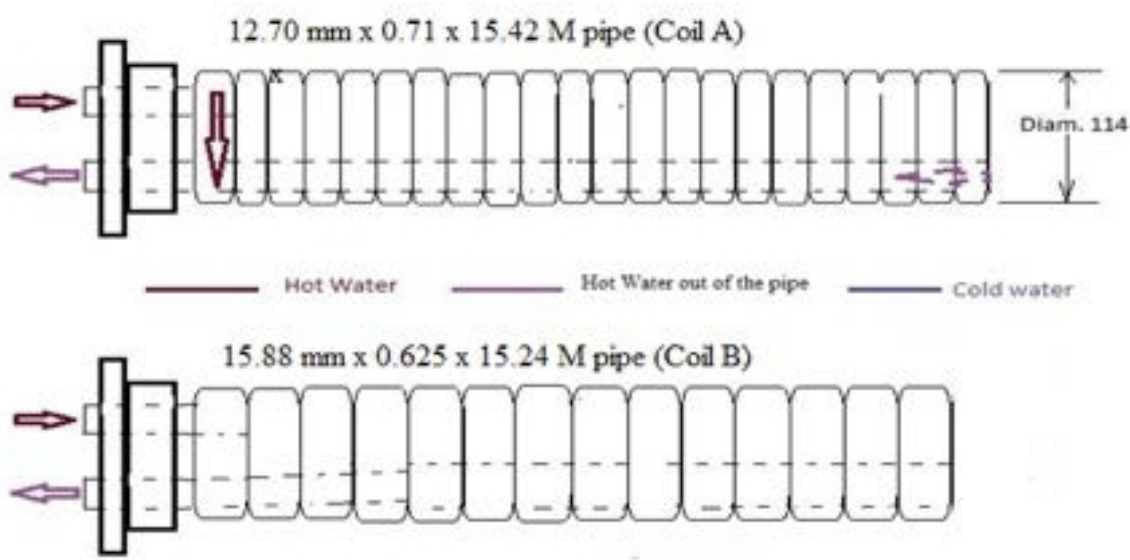

Figure 4: Dimensions of the final copper piping heat exchanging coils, Heat Exchanger Coil $A$ and Heat Exchanger Coil B

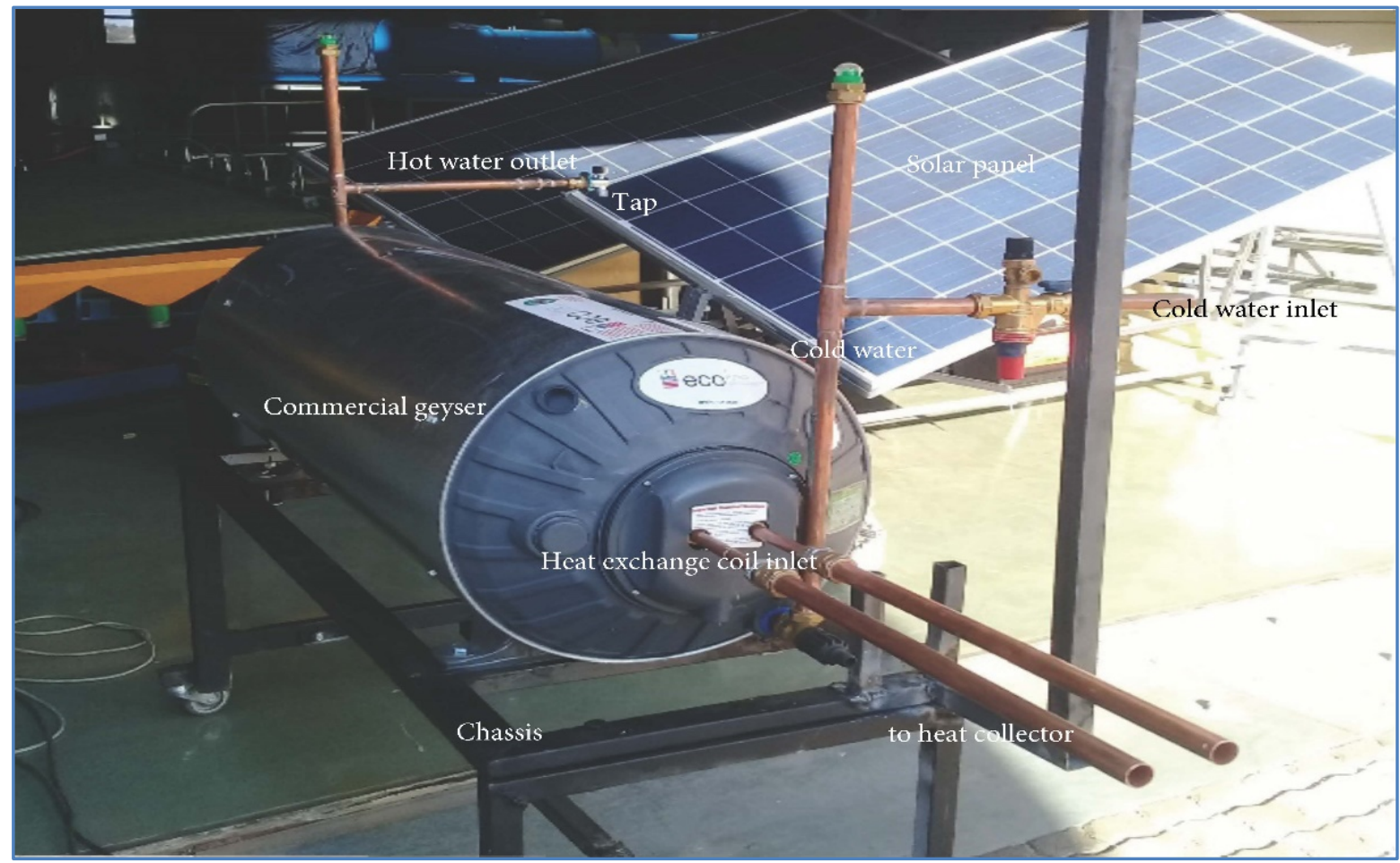

Figure 5: Photograph of the adaptive solar heat reservoir and solar circulation pump system developed at the Unisa laboratories 


\section{Results}

\subsection{Efficiency of heat exchange along the coils}

The overall heat exchange along the respective coils when the coils were supplied with a constant flow of water at $42{ }^{\circ} \mathrm{C}$ was tested. The coils were fed with water that was kept at a constant temperature in a second supply reservoir. To test the efficiency of each heat-exchanging coil, each exchanger was divided into seven segments (sections 1 to 7 ) along the coil and an appropriate temperature testing point was allocated to each section. Hot water at $42{ }^{\circ} \mathrm{C}$ was then circulated from a second reservoir with the aid of the solar pump. This procedure was followed to ensure a constant inlet temperature into the heater coils. The temperatures were then measured at each test point along the coils after the water had circulated for about five minutes. Figure 6 shows two temperature profiles for the test heat-exchanging Coil $A$ and heat-exchanging Coil B after 15 minutes of circulation.

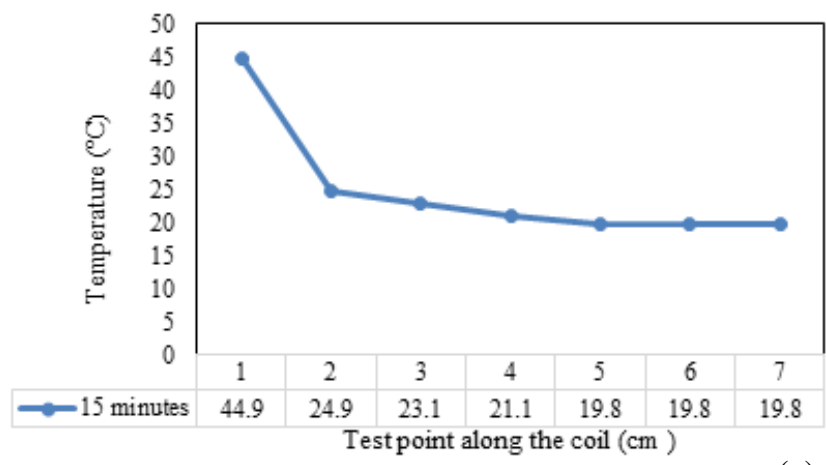

(a)



(b)

Figure 6: Temperature profiles along the respective heat-exchanging coils after 15 minutes of circulation, starting with cold water $\left(23^{\circ} \mathrm{C}\right)$ in the geyser. Fig. (a) gives the temperature profile along the heatexchanging Coil A (diameter of pipe $=13$ $\mathrm{mm}$, length of copper tubing $=\mathbf{1 5 . 2 4} \mathrm{m}$ ); and Fig (b) the temperature profile along heat-exchanging Coil B (diameter of copper pipe $=16 \mathrm{~mm}$, length of copper coil = $15.42 \mathrm{~m})$.
The thin pipe coil, with $13 \mathrm{~mm}$ diameter piping, showed a very short heat-exchange profile along the coil, indicating that heat exchange occurred only over the initial sections of the coil. The thinner piping heat-exchange transfer was hence much faster, since the total heat energy injected into the heat exchanger was dissipated over a much smaller section of the coil. In the thicker pipe, because of the bigger surface area of the larger diameter pipe, the heat exchange seemingly occurred over a much larger section of the coil, which could have resulted in a much higher total transfer of heat from the coil to the water.

\subsection{Overall performance of the heat- exchanging coils}

In this test, the overall performance or heat-transfer capacity of the heat exchangers was tested by heating 150 litres of water in the geyser from a temperature of $23^{\circ} \mathrm{C}$. The inlet temperature of the water was kept constant in a second supply reservoir, while the practical real temperatures of the receiving geyser were monitored at (1) the inlet of the heat-exchanging coil, (2) the outlet of the heat-exchanging coil and (3) at the outlet of the geyser itself. Figure 7 illustrates the observed results.

The overall results indicate that for heat-exchanging Coil A (thin tubing), the water in the geyser reached a geyser temperature of $40{ }^{\circ} \mathrm{C}$ within only 30 minutes of heating time. In heat-exchanging Coil $\mathrm{B}$ (thick tubing) the water rise in the geyser was very gradual; the water in the geyser took about 60 minutes to be heated to reach $40^{\circ} \mathrm{C}$ (Figure 6b). The total eventual temperature of the volume of water in the tank over the same period was $45^{\circ} \mathrm{C}$. The latter slower heating times observed for Coil B are presumably the result of lower heat transfer from the centre of the pipe to the walls of the pipe in the larger pipe. The slower heating of the reservoir water at the later stages of heating both cases is attributed to the smaller temperature differences between the circulated water in the tubing and the reservoir water, according to Equation 2 above. In both cases, however, the reservoir temperature was still increasing at a steady rate, indicating that the heat transfer from the coils was still present and effective even at high reservoir/geyser temperatures. The slight oscillations observed in the temperature profiles are attributed to the specific way the measurements were conducted, the time needed for the system to equalise during circulation and thermal syphoning inside the reservoir. The above results basically confirm the theoretical predictions that were derived in Section 2. 


\subsection{Performance of the heat-exchanging coils when hot water was drawn from the reservoir geyser}

Figure 7 illustrates the behaviour of the temperature of the water in the tank reservoir when 20 litres of water are taken from the geyser at once. Temperatures were taken every 15 minutes. The curve represents the variation in the geyser's water outlet temperature. This test, generally, confirms the previous results for the overall heating of the water in the geyser. Particularly impressive was the fast recovery time of the system after water had been extracted from the system. On the graph, the coordinate represents the progress of the time of exchange and heating of the water in the tank. There are 15 minutes between two points on the line. Thermal efficiency (E) of the construct was calculated with Equation 13.

$$
\mathrm{E}=\frac{(T c o-T c i)}{(T h i-T h o)} * \frac{1}{R}
$$

with $\mathrm{R}$ the coefficient of imbalance:

$$
\begin{aligned}
& \mathrm{R}=\mathrm{T}_{\mathrm{co}}-\mathrm{T}_{\mathrm{ci}} / \mathrm{T}_{\mathrm{hi}}-\mathrm{T}_{\mathrm{ho}} \text { and } \\
& \mathrm{E}_{\mathrm{c}}=\mathrm{Tco}-\mathrm{Tci}_{\mathrm{ci}} / \mathrm{T}_{\mathrm{hi}}-\mathrm{T}_{\mathrm{ci}} \\
& \mathrm{T}_{\mathrm{hi}}=73.0{ }^{\circ} \mathrm{C}, \mathrm{T}_{\mathrm{ho}}=50.8{ }^{\circ} \mathrm{C}, \mathrm{T}_{\mathrm{ci}}=46.3{ }^{\circ} \mathrm{C} \text { and } \\
& \mathrm{T}_{\mathrm{co}}=48.0{ }^{\circ} \mathrm{C} .
\end{aligned}
$$

Thus, $\mathrm{E}=\frac{(73-50.8)}{73.0-46.3}=0.83$

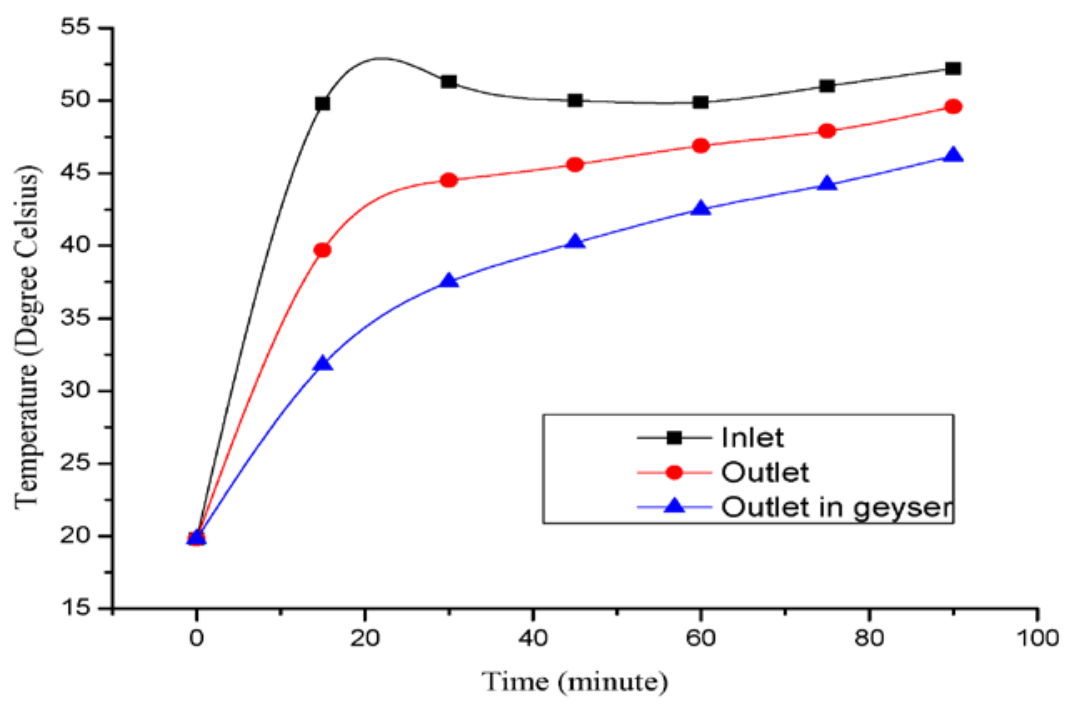

a)

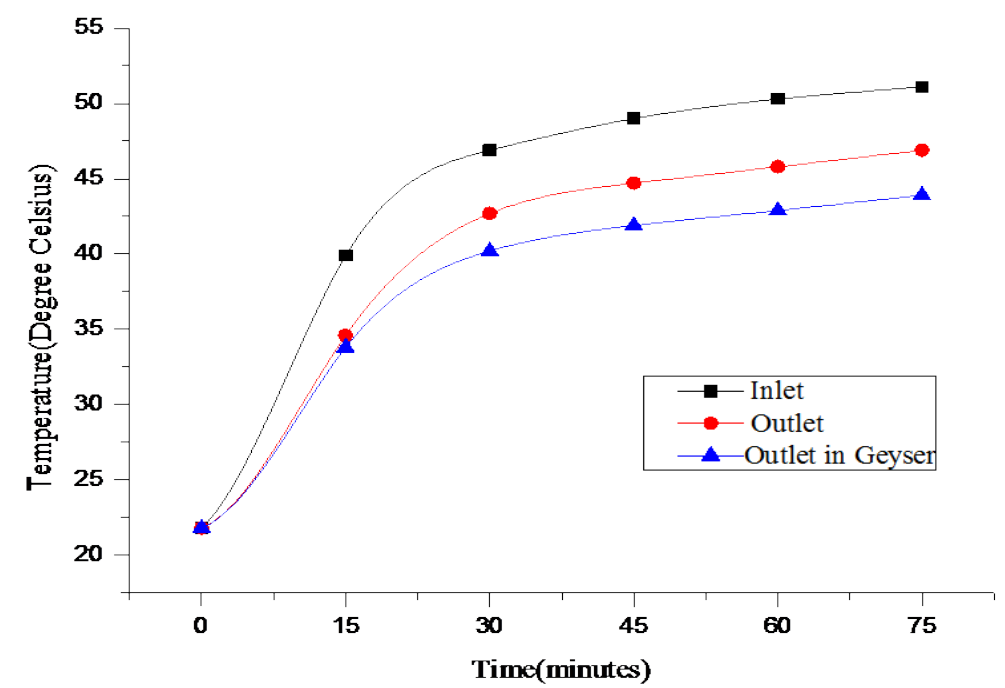

b)

Figure 7: Overall performance of the system with heat exchangers when heating 150 litres of water in a receiving geyser (a) for Heat-exchanger A (small copper piping) and (b) for Heat-exchanger B (large copper piping). 


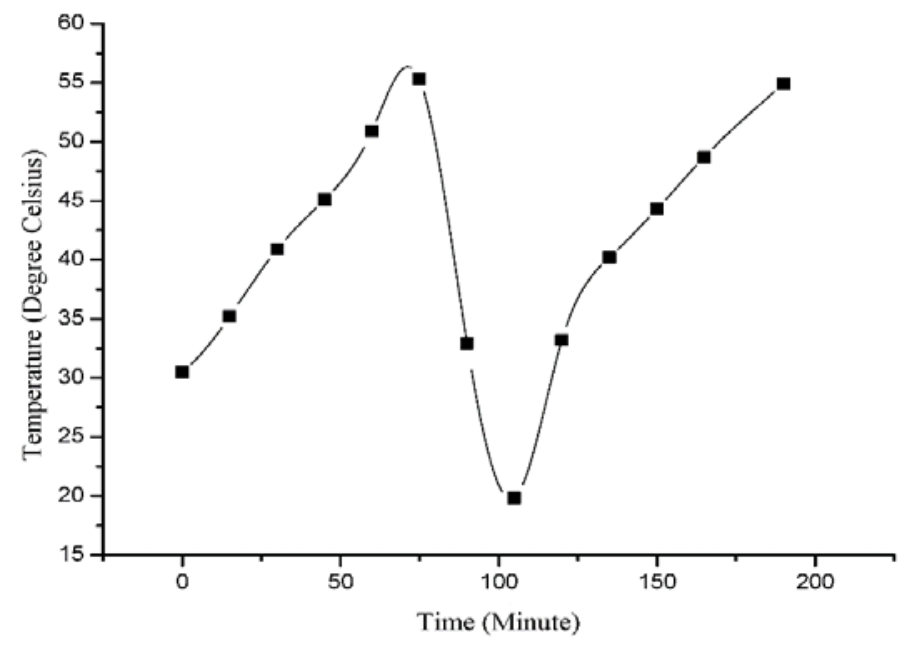

Figure 8: Temperature variations with Heat-exchanging Coil $A$ in the geyser when hot water is extracted from system, illustrating the fast recovery time of the system

\subsection{Cost of the system}

The entire prototype system was built using local materials that are commercially available in South Africa. The total purchase price of all the materials used in the construction of the adaptive tank heat exchanger was ZAR 6 745. If the system were combined with a low-cost heat collector at ZAR 5000 , the total cost of the heat-collection system would be approximately ZAR 12000 . The total capital outlay of ZAR 12000 required is approximately half of the cost of a standard integrated solar water-heating system that is commercially available in South Africa (One Energy Company, 2018).

\subsection{Estimated saving}

This calculates how much a household using this system would save over a ten years, which is the estimated lifetime of the system. The present study first estimated the usage cost of an electric geyser system, which included the price of purchase and the total cost of electricity in kWh per month over ten years. All the data on electric water-heating billing were obtained from the Eskom website (Eskom Residential Appliance Calculator, 2018). and are applicable to a five-member household of $240 \mathrm{~m}^{2}$ with a geyser thermostat setting of $70{ }^{\circ} \mathrm{C}$. In the household, the total monthly usage of electricity for water heating is $860 \mathrm{kWh}$ at a cost of ZAR 108 per month. As the total monthly electricity cost of ZAR1 208, the annual cost would be ZAR 14 500. Over a ten-year period, with $6 \%$ escalation in grid supply cost, the cost would be approximately ZAR 120 000. If the system purchase is considered, the total amount would be ZAR $72500+$ ZAR 3000 = ZAR 75500 . The designed adaptive heat-absorbing and heat-exchange system would cost only ZAR 12 000. Thereafter water heating is largely free and only maintenance costs has to be taken into consideration.

This analysis demonstrated the following potential saving to households using the hybrid low-cost solar heat-absorbing and heat-exchange system: Assuming a $30 \%$ bad weather cycle per month, and assuming enough solar heat collection in winter to supply all hot water needs, the remaining electricity bill over a ten-year period would be approximately amount to ZAR 60000 - a saving of approximately ZAR 140000 over a ten-year period and a once-off capital outlay of approximately ZAR 12000 . This means that a household could save about ZAR 800 per month. A final derivation is that if the capital outlay is paid as an initial once-off payment, the outlay will be recovered in approximately 15 months. In the case of low-cost housing schemes, these costs could be absorbed in the initial capital outlay of the scheme and the dependency on the grid electricity could be reduced by about $60 \%$. Assuming an average collection for a $4 \times 4$ metre absorber panel of 10 $\mathrm{kWh} \times 6=60 \mathrm{kWh}$ per day $=400 \mathrm{kWh}$ per week $=1500 \mathrm{kWh}$ per month $=180000 \mathrm{kWh}$ over a ten-year period (given optimal weather) and an initial capital outlay of only ZAR 12000 , the estimates relate to an effective initial cost of ZAR 0.12 per $\mathrm{kWh}$ for the system.

The tests hence show that the system of approximately $15 \mathrm{~m}^{2}$ area can be installed at a cost of approximately ZAR10 000-12 000. The system can provide hot water to a household in South Africa at approximately 12 cents per $\mathrm{kWh}$, with a total heat storage capacity of up to $10 \mathrm{kWhrs}$ per day. This implies a saving to the customer of up to ZAR 600 per month. The accumulated saving to a household over the ten year lifetime of the product is estimated at ZAR 200 000. As the thermal energy storage capacity of current systems as available on the market in South Africa are approximately $1 \mathrm{kWhr}$ per day for a 1 square meter collector, this imply about a ten fold higher thermal energy collection capability as compared to conventional commercially available systems in South Africa. 
Table 2: Estimated savings associated with the utilisation of the system.

\begin{tabular}{|c|c|c|c|c|c|c|c|}
\hline $\begin{array}{l}\text { System in } \\
\text { operation }\end{array}$ & $\begin{array}{c}\text { Capital } \\
\text { outlay } \\
\text { (once-off) } \\
\text { (ZAR) }\end{array}$ & $\begin{array}{l}\text { Monthly } \\
\text { usage cost for } \\
\text { water elect- } \\
\text { rical heating }\end{array}$ & $\begin{array}{l}6 \text { months } \\
\text { usage cost } \\
\text { (ZAR) }\end{array}$ & $\begin{array}{c}\text { One-year } \\
\text { usage cost } \\
\text { (ZAR) }\end{array}$ & $\begin{array}{c}10 \text { years } \\
\text { usage cost } \\
(Z A R)(6 \% \\
\text { escalation } p / a)\end{array}$ & $\begin{array}{c}\text { Estimated con- } \\
\text { ventional } \mathrm{kWh} \\
\text { usage over } 10 \\
\text { years }\end{array}$ & $\begin{array}{c}\text { Initial cost per } k W h \\
\text { (current electricity } \\
\text { tariffs in South Af- } \\
\text { rica) }\end{array}$ \\
\hline $\begin{array}{l}\text { Conventional electric } \\
\text { geyser }\end{array}$ & 3000 & 1208 & 7249 & 15000 & 200000 & 120000 & ZAR 1.85 per kWh \\
\hline $\begin{array}{l}\text { Low-cost large-area solar } \\
\text { energy-absorbing and } \\
\text { heat-exchange system }\end{array}$ & 12000 & 300 & 1800 & 3600 & 60000 & 40000 & ZAR 0.12 per $\mathrm{kWh}$ \\
\hline
\end{tabular}

\section{Conclusions}

The following conclusions are derived from this study:

- By using a low pressure large area heat absorber, and low cost materials for the heat absorber, very large amounts of heat can be collected which is much larger as offered by current systems sold on the SA market, typically up to $400 \%$ larger.

- The system offers a major advantage that the heat absorber operates at low water pressure, while the geyser operates at high pressure and that can be connected to the standard watersupply system an urban water supply grid.

- It is possible to obtain good performance as well as large cost savings by adapting a low-cost large-area, flat roof, heat absorber and heat exchanger coil into a standard household geyser, and adding additive technologies such as a heat exchanger coil, a few switches and a solar powered pump to drive the circulation of the system.

- Further adaptive components can be added to the system, such as a final stage flat plate insulated glass cover absorber in order to further augment the final achievable temperature. The geyser reservoirs can also be mounted below roof level and small solar driving panels can be used to circulate the thermal energy as collected and stored. As a result of these features, the developed system is much more aesthetically pleasing than other systems currently available and installed in South Africa. Another option is to mount the low cost reflector and piping absorber systems vertically against walls which are facing the sun for most of the day. These could indeed appeal aesthetically and architecturally as well.

- The system can be incorporated in both lowcost and high-cost housing environments in South Africa.
- The estimated cost of using the system as developed in this study is 12 cents per kWh, which includes the once-off capital outlay, installation costs and a ten-year lifecycle.

- The technology and designs developed in the study have the potential to create many new business opportunities in South Africa, in both urban and rural areas. These opportunities include the manufacturing, installation and maintenance of unit. These aspects are all labour intensive, which can lead to the creation of many new job opportunities in South Africa and the rest of Africa.

\section{Acknowledgements}

We would like to thank the Department of Electrical and Mining Engineering in the College of Science Engineering and Technology at the University of South Africa for their financial assistance in conducting the research. The content of this article forms the subject of RSA Patent No. 567745 of 2008, RSA Patent No. 1508 of 2012 and RSA Patent 05297 of 2016 (SA Patent Journal, 2008, 2012 and 2016). The intellectual property emanating from the study belongs to the University of South Africa. The intention is to make this technology available to the broader public and business sector of South Africa through appropriate licensing actions, while a small portion of the wealth that is generated from the technology transfer will be channelled back to Unisa to promote further development actions.

\section{References}

Christophe, W \& André, M. 2016. Les échangeurs de chaleur. Encyclopédie de l'énergie: Article No. 55. Available at: https://bit.ly/2HMACLN (accessed on 1 August 2017).

Eskom Residential Appliance Calculator. 2018. Available at: http://eskom-idm-residential-toolswebapp.fogg.za.com/web/\#_ (accessed on 1 August 2017.

Lienhard, John IV, and Lienhard John V., 2011. A heat transfer textbook. 4th edition. Cambridge: Cambridge University Press:49. 
One Energy Company. 2018. Available at: http://www.oneenergy.co.za/prod-

ucts.asp?P_ID $=150 \&$ type $=2$ (accessed on 1 August 2017)

Price Check Company SA, 2018, available at: https://www.pricecheck.co.za/search?search=solar+geyser (accessed on 1 August 2017).

Saha, S.K., Tiwari, M., Sundén, B., Wu, Z. 2016. Advances in heat transfer enhancement. Basel: Springer International: 4 .

Schreyer, CDR., 2011. Simulation of energy use in residential water heating systems. Master of Applied Science thesis, Department of Mechanical Engineering, University of Victoria:7.

Cengel. Y.A., 2016. Heat Transfer: Practical Approach. 2nd edition.Amazon.com:17-18.

Snyman, LW., 2008. Smart controller for a household solar energy backup system. RSA Patent Journal, Patent 2008/567745 of May 2008. Granted: SA (2009/3071).

Snyman, LW., 2012. High pressure low pressure thermal energy collection system. RSA Patent Journal, Patent 2012/1508.

Snyman, LW. 2016. Integrated roof solar thermal energy collector. RSA Patent Journal, Patent SA 2016/05297.

Tobaly, P. 2002. Échangeurs de chaleur. Licence professionnelle thesis, IUT of St Denis, GPI:10-11. 